\title{
IRIA CANDELA: SOMBRAS DE CIUDAD. ARTE Y TRANSFORMACIÓN URBANA EN NUEVA YORK 1970-1990
}

Madrid: Alianza Formas, 2007. 228 páginas. Formato 23x17,6 cm. ISBN 978-84-206-4868-2

Ángel Martínez García-Posada

Dr. arquitecto. Profesor. Departamento de Proyectos Arquitectónicos. Escuela Técnica Superior de Arquitectura.

Universidad de Sevilla. España.

Persona de contacto: angelmgp@gmail.com

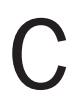

uando Alianza Forma editó Sombras de ciudad en 2007, la crisis económica que habría de marcar la década siguiente aún no había eclosionado, aunque hoy sabemos que todos sus resortes, vinculados al ansia voraz de expansión económica sin control, estaban ya activados. Iria Candela, historiadora y crítica de arte, analizaba en su lúcida secuencia de episodios algunas prácticas artísticas críticas desarrolladas en esa ciudad en los años setenta y ochenta, un periodo marcado también por dos procesos antagónicos: el orgulloso renacimiento urbano fruto de los procesos de conversión de la ciudad en un escenario global frente a los traumáticos efectos de declive y abandono que estas transformaciones habían provocado en algunas zonas de la capital. Aquella catarsis dio lugar a una serie de propuestas artísticas heterogéneas hábilmente entrelazadas narrativamente por Candela, que se valían de la ciudad como contexto y evidenciaban los aspectos problemáticos de esta evolución urbana, fundamentalmente a través de los registros expandidos de la escultura pública y la fotografía.

Candela desarrolló su investigación con una cierta distancia temporal respecto a los hechos abordados que otorgaba una deseable perspectiva a sus valoraciones. Quizás hoy, en esta relectura de su texto, podríamos empezar a preguntarnos cuál podría ser el apunte de relato de las consecuencias de la última crisis en la ciudad contemporánea para alcanzar a componerlo en algún momento futuro. Para este discurso por hacer, el libro de Candela resultará una referencia oportuna, pues entre uno y otro momento existen algunas analogías evidentes, y otros tantos matices diferenciales en virtud de la tecnología de la información y las posibilidades de internet sobrevenidas desde entonces. Nos cabe cuestionarnos si algunas proposiciones artísticas en este último decenio alcanzan el estimable valor, elocuente y artístico, de aquellas que en su obra detallaba Candela, si bien carecemos todavía de esa visión no tan inmediata que los historiadores aconsejan.

Quizás por esta posibilidad de enlazar los estudios de las producciones artísticas acaecidas en los márgenes del sistema en diversos periodos convulsos recientes, dientes de sierra de nuestra historia próxima, debiéramos asimismo evocar un libro esencial como acta de la metamorfosis experimentada por el arte en el último medio siglo, Seis años: la desmaterialización del objeto artístico. De 1966 a 1972, de Lucy Lippard, del cual el mismo subtítulo de Candela, Arte y transformación urbana en Nueva York, 1970-1990, es deudor casi con vocación de encadenamiento. Los ensayos de Lippard y Candela, con tantas concomitancias pese a sus diferencias estructurales -el primero es un prolífico dietario que da cuenta a pie de campo, in progress, de la frenética actividad artística en aquellos años cruciales en la ciudad y el segundo una elaborada disertación en capítulos con subtítulos sugerentes, cuidadas conclusiones parciales y asociaciones argumentadas -, se refieren al escenario neoyorquino mientras que en ese otro que aún está por escribir la importancia paradigmática de Nueva York parece diluirse ya en un mundo interconectado. La cartografía sistemática de las malas calles que trazaba Candela, que a partir de un preámbulo warholiano tomaba en cada capítulo a una figura central - de este modo iban desfilando Gordon Matta-Clark, Hans Haacke, Martha Rosler, Camilo Vergara, Richard Serra, Tehching Hsieh, Krzysztof Wodiczko y Frances Torres- que en cada caso se iba entreverando con otros autores relacionados, se mantiene apenas alterada: Matta-Clark, Serra o Haacke son hoy tan influyentes como hace diez años, de manera que aparecerían en el sustrato de 
cualquier compendio de actuaciones contemporáneas relevantes; a Wodiczko y sobre todo a Hsieh, con sus líricas performances de resistencia hasta su intencionada evasión anónima, sigue sin conocerlos nadie.

El mismo año en que se publicaba el texto de Candela, lo hacía Warhol's Dream, de Saul Anton, que ficcionaba la conversación en dos largos paseos por Manhattan entre Andy Warhol y Robert Smithson. Aunque se trata de un libro ocurrente, y un punto frívolo, en contraste con el encomiable rigor académico de Candela, se hacía indudable que Anton había estudiado bien los discursos de estos dos artistas hasta interiorizarlos de modo que la charla lograba emular las características dialécticas de ambos polos, tan distantes entre sí pero a la vez tan iluminadoras para otros autores que los tomaron, a uno u a otro, como guía. Pese a la aludida diferencia de carácter entre sendos textos, al haberlos tenido entonces a la vez sobre la mesa, leyendo el primer capítulo del libro de Candela, dedicado a Matta-Clark - quizás el autor más presente a lo largo del mismo, y que desde ese inicio va apareciendo como modelo en varios otros pasajes, así la filiación del Shapolsky et al. Manhattan Real State Holdings de Hans Haacke con sus Reality Properties: Fake States, o la retórica del deterioro urbano del Bowery de Martha Rosler con los fragmentos de edificios cortados del anarquitecto - no pude evitar pensar que hubiera sido igualmente interesante la conjetura de imaginar las conversaciones entre Matta-Clark y Smithson.

Sombras de ciudad comienza presentando a Matta-Clark como colaborador de los artistas participantes en la muestra Earth Art celebrada en 1968 en el campus de la Universidad de Cornell, en Ithaca, una región boscosa al norte de Nueva York, donde él se graduaría como arquitecto. Ello le permitió conocer tempranamente a Smithson, la figura que más le influiría desde entonces. En Ithaca asistió a Dennis Oppenheim en su acción de cortar con una motosierra la superficie de un lago helado, y seguidamente trabajó con Christo y Jeanne-Claude en Valley Curtain, la cortina que atravesaba varios condados de California. Candela señala que Matta-Clark iba camino de hacerse un hueco dentro de ese grupo variopinto llamado a renovar el panorama artístico mediante intervenciones específicas en la naturaleza. Sin embargo, pronto habría de tomar otra senda bifurcada, cuando al instalarse en Nueva York queda impactado por la efervescencia de aquella ciudad en bancarrota. Desde esta iluminación por las tinieblas de la ciudad empezaría a interesarse por otra suerte de paisaje, urbano y social, que devendría indisociable de su obra, hasta convertirse, como Candela apunta con acierto, en un artista bisagra que serviría de nexo entre las prácticas del Land Art , las cuales permanecerían como un sustrato fundacional de su obra, y las materializaciones del arte urbano que empezaban a ensayarse en el contexto de Nueva York reinterpretando aquellas en este nuevo ámbito de la ciudad agitada.

Candela retrata a Matta-Clark como un tipo activo y sociable, que gustaba de cooperar con otros artistas en este momento álgido, a comienzos de los años setenta, cuando muchos autores se agrupaban en torno al SoHo para ensayar formas colaborativas de trabajo y desplegar modelos de exhibición alternativos, y que recelaba de la perspectiva de aislarse durante meses en el desierto para hacer círculos en la arena. Como la ensayista precisa, aunque su interés conceptual tenía que ver con la noción de entropía, según había aprendido de Smithson, su tema habría de ser el de las ruinas y desechos de la ciudad. En cierta ocasión en que le preguntaron la razón de Day's End, aquel agujero abierto en la nave desahuciada 
N18_ARQUITECTURAS AL MARGEN

124

junto al muelle, adujo que su intención era dejar una marca en un momento triste de la historia, hacer una contribución artística a "una ciudad en decadencia". Sin necesidad de acudir al desierto, la urbe industrial en degradación le ofrecía un campo de fenómenos entrópicos, alegorías de la destrucción urbana, más cargado incluso que las minas abandonadas de Smithson, y que en su corta e intensa deriva, iría tornando más hacia lo social y menos a lo energético. Había estudiado arquitectura, la ciudad satisfacía sus inquietudes artísticas, fragmento a fragmento sustraído, iría descubriendo en ella nuevos espacios para el arte, tal que sus suelos robados o sus despojos de solares. Acaso fuera esa, como de nuevo explicita Candela con finura, su manera de entender la dialéctica smithsoniana del site y el non site.

Este consuelo en la penumbra, el de redimir destinos crueles, bien pudiera ser el mismo que, hace unos pocos años, nos viniera a recordar Haacke en su visita a España, con motivo de una muestra de su obra en el Reina Sofía, Castillos en el Aire. El artista concibió una certera obra específica que ligaba el marco que lo acogía con su propia trayectoria - los ecos de Shapolsky et al eran claros, por ejemplo- y explicaba la elección del título, que, además de una imagen de cuento, era otro de esos sintagmas que designaban nuestra reciente situación de crisis inmobiliaria. Haacke documentaba el significativo caso de un nuevo barrio de la zona meridional del Ensanche de Vallecas abandonado en pleno proceso de urbanización. Este enclave inacabado cobraba una nueva luz frente a la oscuridad de aquella crisis por el punctum de su toponimia, en la que cada calle designaba algún movimiento artístico contemporáneo. Tal vez esta obra debiera contarse en ese libro por escribir sobre estos años. 